Maurice A. Deane School of Law at Hofstra University Scholarly Commons at Hofstra Law

Hofstra Law Faculty Scholarship

2004

\title{
The Model Standards of Practice for Family and Divorce Mediation
}

Andrew Schepard

Maurice A. Deane School of Law at Hofstra University

Follow this and additional works at: https://scholarlycommons.law.hofstra.edu/faculty_scholarship

\section{Recommended Citation}

Andrew Schepard, The Model Standards of Practice for Family and Divorce Mediation Divorce and Family Mediation : Models, Techniques, and Applications 516 (2004)

Available at: https://scholarlycommons.law.hofstra.edu/faculty_scholarship/653

This Book Chapter is brought to you for free and open access by Scholarly Commons at Hofstra Law. It has been accepted for inclusion in Hofstra Law Faculty Scholarship by an authorized administrator of Scholarly Commons at Hofstra Law. For more information, please contact lawcls@hofstra.edu. 


\title{
CHAPTER 22
}

\section{The Model Standards of Practice for Family and Divorce Mediation}

\author{
ANDREW SCHEPARD
}

Andrew Schepard served as Reporter for the development of the Model Standards of Practice for Family and Divorce Mediation. This chapter recounts the historical development of the Standards and discusses how they address professional and ethical issues germane to good practice.

The rapid growth of private and public family and divorce mediation services has created a need for quality control to protect consumers as well as to protect the credibility of an evolving profession. Unprofessional mediation practice can cause serious damage to participants and the profession. A demand for quality control, in turn, means that interested stakeholders and the public recognize that mediation is a valuable partner with courts and lawyers in the process of resolving family disputes (Schepard, 2000).

Creating quality control means that someone has to define what constitutes good mediation practice. The profession itself recognized the importance of undertaking that task, in consultation with other interested mediation stakeholders, such as the bar and family violence groups, by creating a process for dialogue that ultimately led to the Model Standards of Practice for Divorce and Family Mediation (Model Standards). (See Appendix 22.1 at the end of this chapter for the full text of the Model Standards.)

Development of the Model Standards helps the mediation profession because the document provides guidance as to what constitutes high-quality practice that meets the special needs of participants and children involved in family and divorce disputes. Mediators working with this population face numerous special challenges. Children exposed to continuing parental conflict 
are predictable casualties.of family disputes; in no other area is the welfare of so many morally innocent and socially important «nonparticipants so regularly at stake. Important legal rights such as custody, child support, and property distribution are affected by agreements reached. in mediation. Family disputes often produce especially intense emotional stress, which can cloud participants'judgment: The context of a family dispute can include domestic violence, child abuse, participant incapacity due to mental "illness. or substance abuse, and cultural differences between family members and between participants and the mediator. For the first time in the history of theimediation field in the United States, the mediation practitioners, whatever their profession of origin, can seek guidance on the generally agreedsupon and recommended approaches to performing "their role in these especially intense circumstances.

This chapter has a modest aim: to introduce the Model Standards to those not familiar with them. It provides an overview of the standards, the process of developing the documents, and their most important thémes. Family and divorce mediation is a complex and evolving field;' this 'comparátively brief article thus. cannot touch on all of the issues and problems addressed by the Model Standards. Many. of the other chapters in this volume elaborate on the subjects mentioned here in more detail and nuance.

\section{.WHAT ARE THE MODEL STANDARDS?}

The Model Standards contain consensus standards for "good family and $\mathrm{di}^{\mathrm{t}}$ vorce mediation practice and thus provides a concrete and:concise definition of the mediator's role. The document consists of 13 general principles followed by specific, detailed practice considerations regarding the implementation of each principle. The Model Standards are designed to provide guidance to family" and divorce mediators on problems that are encountered in day-to-day practice, as well as to serve as a primer for training current and future mediators. Furthermore, the document is intended to help the public and allied professionals in the courts, law offices, therapy centers, and community groups clarify what they and their clients ${ }^{*}$ can expect from a family and divorce mediator:

The Model Standards apply to mediators working:in"both private practice' and' court-based mediation programs. (The document includes a special appendix of provisions that is particularly applicable to court-based programs.) The standards also apply to all mediators-lawyers and therapissts alike-regardless of their profession of origin. A comprehensive 'definition of "family disputes" to which the standards are applicable is not attempted. Most mediation' in court-based" programs' occurs in 'response to disputes between parents arising out of separation and divorce. Private mediation practitioners often mediate divorce- and sepáration-relatếd finan- 
cial issues in their practices. The Model Standards can also be applied to mediation in grandparent visitation disputes, child protection mediation, and any other family dispute.

A standard was included in the Model Standards only if symposium participants (described in the next section) reached a consensus that it encapsulated desirable practice norms. As a result, the Model Standards do not address some controversial questions, such as the appropriate balance between "facilitative," "evaluative," and "transformative" approaches to mediation-a subject of much discussion in the mediation community and addressed elsewhere in this volume. The Model Standards leave this, and similar practice issues on which the mediation community has reached no consensus; to the judgment of the mediator and the marketplace in which consumers choose mediators; these consumers will, we hope, choose wisely and with ample information about their chosen mediator's approach to mediation. When a consensus develops on this topic, old standards can be modified and new ones created.

The ModeliStandards are an aspirational resource document for organizations and individuals that wish to adopt them voluntarily. The profession itself has established a recommended code of ethics. Sanctions for violations are prosinces of the organizations that adopt the Model Standards. This document is not a restatement of the law of family mediation for purposes of determining malpractice liability in civil or regulatory proceedings. Nor is it designed to be applied by administrative agencies that regulate mediators or the various professions from which mediators originate. Legislatures, courts, and voluntary professional organizations that do regulate mediation practice may, of, course, find the Model Standards a useful starting point for creating their own standards. The guidelines have not, however, been created for that purpose.

\section{HOW WERE THE MODEL STANDARDS CREATED?}

The Model Standards were developed through a process begun by the Family Law Section of the American Bar Association and facilitated by the Association of Family and Conciliation Courts (AFCC). The process of drafting and redrafting the standards was collaborative and infused with substantial expertise, including consultation with as many interested constituencies as was feasible. The process encouraged communication and bridged differences between the family mediation community, the bar, and domestic yiolence advocates: :

Creation of the Model Standards is the latest milestone in a nearly 20 year-old effort by the family: mediation community to develop and refine standards of practice. Between 1982 and 1984 AFCC،convened three.national symposia on divorce mediation standards. The result of the efforts was the 1984 Model Standards of Practice for Family and Divorce Mediation (Sym- 
posium on Standards of Practice, 1984; hereafter,referred to as "1984 Model Standards"), which alsa'served as a resource docurhent for state and national mediation organizations whose members included many nonlawyer family mediátors and those in court-based programs.

In tandem with the process convened by AFCG, the Family Law Section of the American Bar Association created their own document, Standards of Practice for Lawyer Médiators in Family Law Disputes. (American Bar Assaciation, 1984; hereafter referred to as "1984.ABA Standards"). The 1984 ABA Standards were developed for lawyers who wished to be mediators-at that time, a fole some thought inconsistent with governing standards of professional responsibility for lawyers (Silberman, 1982): The 1984 ABA Standards helped define how lawyers could serve as family mediators' and still stay within the ethical guidelines of their profession.

Following promulgation of the 1984 Model Standards and 1984 ABA Standards, interest in mediation.in all fields-and family mediation, in particularburgeoned. Interested organizations created their own standards of practice for mediation generally.

In 1996, the Family Law Section concluded that a fresh'look at the 1984 $A B A$ Standards was in order. It created the Task Force on Standards of Prac: tice for Divorce Mediation (later renamed the 'Gommittee on Mediation; hereafter referred to as "ABA Committee") to review. the 1984 ABA Standards and make recommendations for changes and amendments. From the outset, the project was conceived as a collaborative effort with other interested groups; membership on the ABA Committee included nonlawyer mediators and liaisons from AFCC, the Academy of Family Mediators, and the Society for Professionals in Dispute Resolution.

After intensive review and study, the ABA Committee concluded that although the 1984 ABA Standards constituted a major step forward in the development of divorce and family mediation practices, they needed to be replaced by a new set of standards for several reasons. First, the 1984 s $A B A$ Standards did not address many critical issues in mediation practice that had arisen since 1984. The document applied only to mediators whose profession of sorigin was law, but many nonlawyers also practiced mediation.. The standards did not distinguish between mediators in private practice and thọse in court-connected 'programs; nor did they deal with domestic violence, "child abuse, and the mediator's role in helping parents define the best interests of their children in their postdivorce parenting arrangements: Furthermore, the document contained no mention of the need for special expertise and training in.mediation, or about family violence and the need for sensitivity to cultural diversity.

Second, the $1984 A B A$ Standards used different language in somer: ar'eas than guidelines for the conduct of mediation subsequently promulgated. The :ABA Committee believed that uniformity of mediation standards among interested groups was needed to provide clear guidance for 
family mediators as well as the public. Uniformity and clarity could not, however, be provided within the framework of the 1984 ABA Standards.

The ABA Committee then examined all available standards of practice, conducted research, and consulted with a number of experts on family and divorce mediation. Committee members focused on the heretofore overlooked issues of domestic violence and child abuse, consulting with experts about the appropriate role of mediation when family situations involved violence or the allegations of these conditions.

The council of the ABA's Family Law Section reviewed the ABA Committee's first draft of new standards of practice in November 1997. It reaffirmed the conclusion that the 1984 ABA Standards should be replaced and invited other interested mediation organizations to participate in the process of drafting new standards. It specifically requested that the ABA Commission on Domestic Violence be included in the consultation process.

AFCC then offered to reconvene the Model Standards Symposium, which had last met in. 1984, using the draft Standards of Practice created by the ABA Committee as the beginning point of the discussion. The aim of reconvening the Model Standards Symposium was to develop a single set of revised standards of practice applicable to all family mediators, regardless of profession of origin. The Family Law Section and the National Council of Dispute Resolution Organizations ${ }^{1}$ joined AFCC in convening the Model Standards Symposium.

In October 1998 the Model Standards Symposium met in Orlando, Florida, to review the draft standards created by the ABA Committee. Representatives of more than 20 family mediation and legal organizations reviewed the ABA Committee draft, line by line, during an all-day session. A draft of revised Model Standards resulted, which was published in the Family and Conciliation Courts Review (since renamed Family Court Review; Symposium on Standards of Practice, 2000). The draft Model Standards were also posted on the websites of AFCC, the Family Law Section, and the ABA Section on Dispute Resolution. Presentations discussing the draft Model.Standards were made at numerous national conferences. In addition, the draft Model Standards were mailed to more than 90 local and national mediation groups for comment.

In response, the symposium received comments and more than 80 proposals for changes in the draft Model Standards. The symposium met again in February 2000 in New Orleans and August 2000 in Chicago to consider these comments and proposals. Attendees at these meetings again included family mediators, family lawyers, and judges in family court from across the nation with years of experience in the field. Many of the participants are leaders in national or local family bar, mediation, and dispute resolution organizations. In addition, the American Bar Association's Commission on Do mestic Violence again participated in the symposium as an expert consultant (Schepard, 2001). 
The Model Standards were revised yet again and approved by the members of the symposium. Their final product was then isubmitted to the various organizations interested in adopting the Model Standards. The governing Councils of the Family Law Section and the Section on Dispute Resolution of the American Bar Association unanimously approved the Model Standards and submitted them to the American Bar Association's House of Delegates (its overall governing body), which adopted them in February 2001. AFCC and other family mediation organizations also have adopted the Model Standards. Thus, as of this writing, the Model Standards have been adopted by a number of groups, including the American Bar Association, AFCC, Connecticut Council for Divorce Mediation, Family and Divorce Mediation Council of Greater New York, Mediation Association of Northwest Ohio, Michigan Council for. Family and Divorce Mediation, and the Wisconsin Association of Mediators.

\section{THE IMPORTANCE OF FAMILY AND DIVORCE MEDIATION}

The Model Standards (reproduced at end of chapter, Appendix 22.1) begin with a definition of mediation, including a statement of what it is and what it is not:

Family and divorce mediation ("family mediation" or "mediation") is a process in which a mediator, àn impartial third party, facilitates the resolution of family disputes by promoting the participants' voluntary agreement. The family mediator assists communication, encourages understanding, and focuses the participants on their individual and common interests. The family mediator works with the participants to explore options, make decisions and reach their own agreements.

Family mediation is not a substitute for the need for family members to obtain independent legal advice or counseling or therapy. (p. 533, this volume)

The Model Standards' basic assumption is that mediation is a dispute resolution process and should be distinguished from, and not confused with, mental health therapy, counseling, or legal representation. "Under the Model Family Mediation Standards, mediators have a special responsibility to make participants aware of the distinction betweerrthe mediator's craft and that of other professionals who might be involved in the family dispute resolution process (Standard IIIA[2 and 4], p. 535, this volume). Even if a mediator is a therapist and uses some techniques in mediation that can be found in therapy textbooks, the service offered-mediation-is different from therapy. The mediator aims to facilitate negotiation between participants to resolve a dispute rather than to effect long-term behavioral change. Similarly, if a mediator is also a lawyer, as a mediator he or she does not represent or provide le- 
gal advice to clients. He or she is a neutral facilitator of negotiations without the professional allegiance to a single client required in the lawyer-client relationship. A participant who'wants individual therapy or independent legal advice must retain a separate professional to do so.

The Model Standards continue with an affirmation of the useful role mediation can play in the resolution of family, disputes:

Nor is it appropriate for all families. However, experience has established that family mediation is a valuable option for many families because it can:

- increase the self-determination of participants and their ability to communicate;

- promote the best interests of children; and

- reduce the economic and emotional costs associated with the resolution of family disputes. (p. 533, this volume)

The Model Standards then recognize that "[s]elf-determination is the fundamental principle of family mediation. The mediation process relies upon the ability of participants to make their own voluntary and informed decisions" (Standard IA, p. 534, this volume).

Mediators who adhere to the practices in the Model Standards thus serve vitally important social goals by promoting participant self-determination and voluntary settlement of family disputes. Voluntary settlements through mediation reduce the emotional and economic transaction costs of resolving family disputes. Reducing those costs, in turn, increases the capacity of mediation participants to function as parents, employees, and citizens. Voluntary settlements through mediation (1) limit the intrusion into family autonomy that results from judicial decrees and allow participants to shape their agreements to reflect their own cultural values; (2) reduce prolonged parental conflict, which causes great damage to children; and (3) give participants "voice" in the process, which makes them more likely to adhere to agreements reached and feel more respect for the process and the society that authorized mediation to occur.

The Model Standards' premise is that most participants in most family disputes benefit from mediation, as does the overloaded court system. That judgment, however, is not a blanket condemnation of litigation, but a call for a diversified dispute resolution system that carefully directs participants to a family dispute process that best serves their needs. Litigation serves vital social purposes. As is discussed shortly, the Model Standards recognize that mediation is not appropriate for all family disputes, particularly those involving domestic abuse. Courts articulate and apply principals of law and resolve factual conflicts. They provide a measure of predictability in outcome by application of precedent and procedures rooted in due process. Theycan require discovery of information that one side wants to keep from the other. They protect the vulnerable and weak against the manipulative and powerful by orders that can be 
enforced with sanctions. Participants and children in some family disputes need these benefits, despite the heavy emotional and financial costs that litigation imposes. Recognizing that some disputes should be litigated, however, does not mean all of them should be. The overall social policy question is how to balance mediation and litigation, not how to eliminate one or the other.

\section{ENTRY INTO MEDIATION}

The choice to participate in mediation belongs to the participants. To make that choice intelligently, participants $\times$ must be aware that mediation is an alternative to litigation and that it has particular benefits and costs. The mediator's authority to perform his or her craft comes from the consent of the participants to enter into mediation, even in court-based programs where participants are compelled to attend atmediation session. The participants may be compelled to attend, but they are.not compelled to speak or agree to anything.

The Model Standards thus create requirements of "informed consent" for a participant's entry into mediation. The mediator must ensure that participants are fully informed about the nature of the process and consent to participate. Standard III requires the mediator to "facilitate the participants' un. derstanding of what mediation is and assess their capacity to mediate before the participants reach an agreement to mediate" (p. 535, this yolume). The mediator is required to provide an overview session. with the participants ber, fore they begin mediation. The Model Standards list what the orientation session must include: a detailed description of what mediation is; how it differs from other dispute resolution processes; that it is voluntary and confidential; exceptions to confidentiality; when and how separate sessions with the participants can be conducted; that court approval may be required for their agreements; that participants are entitled to seek independent advice from lawyers, other professionals of their choice during the mediation process, as well as religious figures and elders, etc. (Standard.IIIA[1-9], pp. 535-536, this volume). The Model Standards also encourage the participants to sign a written agreement, to submit their dispute to mediation 'within a reasonable time after first consulting the family mediator (Standard IIIB, p. 536, this volume). The written agreement should contain terms that describe the mediation process in a way similar to the overview session.

\section{WHO SHOULD MEDIATE?}

The Model Standards define the qualifications for family "mediators in functional terms, not by professional education or background. The qualifica; tions recognize that family disputes have legal, mental health, dispute resolu; tion, and cultural dimensions and that a mediator must be familiar with all 
of them. The Model Standards identify four basic qualities a mediator should possess: (1) knowledge of family law; (2) knowledge of, and training in, the impact of family conflict on parents, children, and others, including knowledge of child development, domestic abuse, child abuse, and neglect; (3) education and training specific to the process of mediation; and (4) the ability to recognize the impact of culture and diversity (Standard IIA[1-4], p. 535, this volume).

Family and divorce mediators thus need education, training, and experience beyond that provided by law, mental health, or general mediation training to meet the criteria established by the Model Standards. A therapist who takes a general mediation training program is not qualified to conduct family and divorce mediation because of his or her lack of familiarity with family law. A lawyer is not qualified to mediate family and divorce disputes without a mediation training program that includes ample information about family dynamics and the impact of culture and diversity on family disputes (Weller, Martin, \& Lederach, 2001).

The Model Standards' stringent requirements should alleviate any remaining fear among lawyers, courts, and the public that mediators are not qualified to help resolve family disputes. In an Appendix of Special Policy Considerations, the Model Standards go even further to urge states and local courts to set standards and qualifications for family mediators, including procedures for evaluations and handling grievances against mediators, in consultation with appropriate professional groups, including professional associations of family mediators (pp. 541-542, this volume).

The Model Standards do not directly address the question of whether a nonlawyer mediator is practicing law or a lawyer mediator is practicing therapy, leaving that subject to regulatory bodies and future task forces (Schwartz, 1999; Beyer, 1998). They do, however, prohibit a mediator from providing therapy or legal advice (Standard VIA, p. 537, this volume). The Model Standards rely on the distinction between a mediator's provision of individually applicable advice (whether legal or therapeutic) versus general information, in stating: "Consistent with standards of impartiality and preserving participant self-determination, a mediator may provide the participants with information that the mediator is qualified by training or experience to provide" (Stan'dard VIB, p. 537, this volume). Thus, a lawyer mediator would be able to provide the participants with general legal information, and a mediator whose profession of origin is in mental health would be able to provide participants with information he or she is qualified to provide, if otherwise appropriate.

The Model Standards also permit the mediator to "document the participants' resolution of their dispute" with the agreement of the participants. Thus, the participants can agree that a mediator will prepare a first,draft of a written settlement resulting from'their deliberations. The Model Standards go on, however, to remind the mediator to "inform the participants that any 
agreement should be reviewed by an independent attorney before' it is signed" (Standard VIE, p. 537, this volume).

\section{CONFIDENTIALITY}

Communications between mediation participánts and the mediator must be confidential for the same réason that communications between a patient and a doctor or an attorney and a clíent áre confidential-to prómote cándớ ánd d frank discussion. Family and divotce disputes often involve intense emotions; otherwise sensible parents say things about themsélves, 'eâch other, and their' children in mediâtion that could come back to haunt them, if disclosed.' Par-' ents (and their lawyers) 'mediating a custody dispute must have confidènce' that their frustrations, hopes, and dreams will not be revealed to a court or the minédia.

Confidentílity also helps ensure that mediation serves its purpose of promoting participant self-determination. A mediator who knows that he or she may be subpoenaed to testify ábout what a parent says or to make a recommendátion to the court for a custody arrangement is likely to gather information to support a position rather than facilitate discussion of shared inter ests. Participants' who know thắt 'a mediátor" might testify or make a recommendation to a court are likely to try to seduce the mediator to join their side. Confidentiálity thus helṕs 'énstứe thát mediation' does nột degenerate into adversarial warfare under another namé.

Standard VII of the Model Standards recognizes the importance of confidentiality in mediation by directing the family" mediator to "maintain the confidentiality of all information acquired in the mediation process, unless the mediator is permitted or required to reveal the information by law or agreement of the participants" (p. 538, this volume). This basic statement of principle, however, also recognizies that męiation cọnfidentiality is subject to exceptions required by other compelling social policicies. A distinguished group from two organizations, the National Commission on Uniform State Laws and the American Bar Association, is currently collaborating on a Uniform Mediation Act. ${ }^{2}$ Unlike the Model Standards, which are practice guidelines directed to family and divorce mediators, the Uniform Mediation Act covers mediation in all subject matter areas, not just fâmily and divorce disputes, and is designed to be enacted by state legislátures. Both the Model Standards and the Uniform Mediation Act, however, aim to guarantee confidentiality in mediation. Both álso recognize exceptions to çonfidentiality for other pressing social values. The Reporter's Notes to the current draft of the Uniform Mediation Act state:

As with other privileges, the mediation privilege must have limits, and nearly all existing state.mediation statutes provide them. Definitions and 
exceptions primarily are necessary to give appropriate weight to other valid justice system values.... They often apply ta situations that arise only rarely, but might produce grave injustice in that unusual case if not excepted from the privilege.

The most important social policy weighing against confidentiality in family and divorce mediation is the need to protect victims of domestic violence and detect child abuse and neglect. There is a strong social consensus that protection of children justifies mandatory child abuse reporting statutes, which radically transform traditionally confidential relationships such as that between doctor and patient. Similar policy considerations justify an exception to the confidentiality privilege for mediation. Furthermore, a mediation, participant threatened by violence cannot be said to be engaged in a process of self-determination because of the coercion the threat creates.

The Model Standards make an exception to the basic principles of mediator confidentiality to protect the safety of participants and children. The mediator is required to report "a participant's threat of suicide or violence against any person to the threatened person and the appropriate authorities if the mediator believes such threat is likely to be acted upon" (Standard VIIC, p. 538, this volume). A mediator is thus required to report any credible threat made by a batterer against a victim of domestic violence. The Model Standards also require mediators to inform participants of any ethically or legally mandated reporting requirements, such as the obligation to report child abuse and neglect, before mediation begins (Standard VIIB, p. 538, this volume).

The Uniform Mediation Act contains a similar exception to confidentiality for threats of violence. Its Reporter's Notes set forth the reasoning behind the exception:

The policy rationales supporting the privilege do not support mediation communications that threaten bodily injury. To the contrary, in these cases disclosure would serve the public interest in safety and the protection of others. Because such statements are sometimes made in anger with no intention to commit the act, the exception is a narrow one that applies only to the threatening statements; the remainder of the mediation communication remains protected against disclosure....

State mediation confidentiality statutes frequently recognize a similar exception. An exception for child abuse and neglect is common in domestic mediation confidentiality statutes, and the Act reaffirms these important policy choices states have made to protect their citizens. ${ }^{4}$

\section{IMPARTIALITY}

The Model Standards establish an expectation that the mediator functions with impartiality in two respects: toward the parties and toward the outcome 
in mediation (Standard IV, pp. 536-537, this.volume). Impartiality toward the parties means thatathe mediator does not have any real or potential'conflict of interest (Standard IVB, p. 536, this volume). A mediator should not mediate a dispute involving a business partner or family member for fear of being perceived as favoring one party over the other. The impartiality principle also means that a mediator should not provide mediation services to clients for "whom the or she has provided other professional services in the past, such as marriage or individual counseling or legal services. While an experienced mediator may be able to separate prior professional services rendered from those now offered in mediation, the possibility of parties' mis' perception is just as important as the reality of the mediator's ability to function effectively, despite serving in a previous toler $A^{*}$ mediator's prior relationship with a participant may haunt, the-mediation process, if another participant perceives that the mediator is not acting in an impartial fashion due to information gleaned from the prior-relationship. For example, a lawyer who'hás drafted a will for one or both of the participants may have had access to financial information that one participant believes may prejudice the mediator's views about property division resulting from divorce. Likewise, a mediator who provided marriage "counseling may be perceived by a participant as having information about the personality and behaviors of an individual that may color the mediator's views about his or her participation in mediation.

1. Impartiality toward the outcome means that a mediator does fiot have any preconceived views about a particular settlement: A.mediator should not lead the parties toward a particular outcome, such as selling the houise or joint custody. The participants are responsible for the outcome, not the mediator.

\section{ENSURING MINIMUM:FAIRNESS IN FACILITATED NEGOTIATIONS}

Impartiality, however, does not imply that the mediator is somerkind of blank slate. A mediator has a spécial responsibility to ensure that the mediation process is fundamentally fair and that optioms are carefully evaluated and considered. For example, a mediator should not sit idly by while one party at: tempts to intimidate the other party into a settlement by threats of violence, nor should a mediator "passively facilitate an agreement that violates fundamental' legal or moral norms.

The Model Standards articulate standards of practice to ensure the use of fundamentally fair bargaining procedures between the participants. The -mediator, for example, "should be alert to' the acapacity and willingness of the participants to mediate before proceeding with the mediation and throughout the process" (Standard IIIC, p. 536, this volume). This provision is designed to ensure that the mediator assesses participants' willingness and ability to mediate before the process begins and throughout its progression. $\mathrm{A}$ 
mediator who believes, for example, that a participant is suffering from a mental illness or is under the influence of drugs or alcohol should not go forward with the mediation session, until the incapacity is recognized and addressed.

The Model Standards also require the mediator to "facilitate full and accurate disclosure and the acquisition and development of information during mediation so that the-participants can make informed decisions. This may be accomplished by encouraging participants to consult appropriate experts" (Standard VIA, p. 537, this volume). The purpose of this provision is to ensure that the participants have roughly equal access to information (such as information about income and assets and medical information about children) essential to fair negotiations and decision making. A mediator must thus be aware of the applicable financial disclosure requirements for divorce disputes and ensure that the participants are also aware of them. Failure to ensure minimum disclosure of necessary information puts potential agreements at greater risk of later challenge and invalidation in court.

The Model Standards do not require, however, that participants must receive exactly the same information during mediation that they do through the discovery process of depositions and document disclosure in litigation. They require only that the mediator ensure minimum disclosure for fairness; participants are entitled to decide, using the advice of outside counsel, if they wish, that the costs of additional disclosure are too great to warrant it. Similar judgments are made in lawyers' offices every day.

The Model Standards also require the mediator to consider suspending or terminating the mediation process if "the participants are about to enter into an agreement that the mediator reasonably believes to be unconscionable" (Standard XIA[4], p. 540, this volume). Unconscionability is a familiar standard in both contract and family law and has a procedural and substantive aspect. This provision imposes a requirement on the mediator to ensure that an agreement is not so unfair that it "shocks the conscience" in the manner in which it was entered (e.g., through threats of physical violence or economic coercion or a complete unwillingness to disclose vital financial information) or because the substantive terms are so wildly unfair that no reasonable person would enter into them (e.g., a complete waiver of child support by a parent who has two children to support and no other source of income). The mediator should apply the unconscionability standard with great restraint, however, in recognition of the importance of self-determination by the parties and maintaining stability in settlement agreements. This standard is designed to ensure that the mediator recognizes that a settlement agreement must satisfy minimum standards of fairness; it does not require that the terms of a mediated agreement be identical to those that would be achieved in a court order after years of discovery and litigation.

The Model Standards are particularly concerned with assuring that the mediator informs participants of their right to consult independent counsel 
and to have counsel participate in mediation, if they so desire. The Model Standards build on the research-based insight that the more that lawyers participate in the mediation process, the more that they support it by developing more settlement-oriented attitudes and filing fewer motions: (Mcewen; Rodgers, \& Maiman, 1995). The Model Standards document should expunge any lingering belief in the' family law bar, that mediators are anti-lawyer. They provide, for example, that " $[\mathrm{b}]$ efore family mediation begins, a. mediator should ... [inform] the participants that they may obtain indépendent ads vice from attorneys ... during the mediation process" (Standard IIIA[4], p. 535 , this volume). The mediator "should recommend that the participants obtain independent legal representation before concluding an agreement" (Standard VIC, p. 537, this volume) and "[i]f the participants so desire, the mediator should allow attorneys, counsel or advocates for the participants to be present at the mediation sessions" (Standard VID, p. 537, this volume).

Although mediators have some responsibility under the Model Standards to help ensure minimum fairness in both the process of bargaining and the substantive outcomes, mediators are not seen as ensurers that agreements resulting from mediation satisfy the preferences of any participant or that the agreement; as a.whole, parallels what a court would award. The tradeoffs between issues and preferences in settlement of a family dispute are too complex, and most substantive family law standards too discretionary, to allow for such routine second guessing of mediated settlements.

.What Model Standards can do, however, is provide assurances to the public and the legal community that the family mediation profession is willing to assume responsibility for ensuring fundamental fairness in facilitated negotiations. While preserving the mediator's role as an impartial oné, the.Model Standards codify good practices in mediation that make it less likely (though, of course, not impossible) for unscrupulous participants to take advantage of the mediàtion process.

\section{MEDIATION AND THE BEST INTERESTS OF CHILDREN}

There is no longer much debate that prolonged parental conflict arising from divorce or separation can seriously damage children emotionally, educationally, and economically (Schepard, 1998; Stern et als, 2000). A major innovation of the Model Standards is that they impose an obligation on the mediator to "assist participants in "determining how to promote the best interests of children" caught in the middle of such family conflict (Standard VIII, p. 538, this volume).

The mediation process generally provides the best interests of children because it emphasizes self-determination and voluntary agreements and helps parents.manage their conflicts responsibly (Schepard, 1985). Most children benefit from having a continuing relationship with both parents after divorce or separation if it is safe for them to do so; mediation is perhaps the 
best dispute resolution process available to help parents achieve that goal through self-determined agreements.

The Model Standards provide concrete suggestions for how mediators can help parents best utilize mediation to promote the best interests of children. However, they do not endorse any particular kind of postdivorce or separation parenting plans (e.g., joint custody, sole custody, or some variation). That decision is for the parents to make with the help of the mediator and their advisors.

Thus, the Model Standards suggest that the mediator encourage parents to obtain information about child development and any pertinent community resources to help their children through the difficulties of family reorganization. The Model Standards also suggest that parenting plans resulting from mediation contain appropriate levels of detail in provisions regarding children's residence and decision-making responsibilities rather than leave parents guessing about matters likely to result in later conflict. It is suggested that the participants address the need to revise a parenting plan over time, as their children's developmental needs change, and to create a process now to resolve future disputes (Standard VIIIA[1-5], pp. 538-539, this volume).

Other provisions of the Model Standards address questions of whether and how the children should participate in the mediation process. The Model Standards do not definitively answer these sensitive questions, instead leaving them for determination by parents in consultation with the mediator. They reinforce parental authority by stating that, except in extraordinary circumstances, children should not participate in the mediation unless both parents and the court-appointed representative of the child(ren) consent (Standard VIIID, p. 539, this volume). The Model Standards also indicate that the mediator should inform the parents about the full range of options available for how children might participate (e.g., direct participation in a mediation, an interview with a mental health professional or the mediator, a videotaped statement) and the costs and benefits of each (Standard VIIIE, p. 539, this volume).

One of the most difficult questions in drafting the Model Standards was to define the relationship between the mediation process and the representative of the children. Many states do not require representatives to be appointed for children in all disputes. In some states, nonlawyers can serve as children's representatives, and their obligations of confidentiality to the child are somewhat undefined. In many states, furthermore, lawyers for children in child custody disputes have ambiguous roles. They may represent a child's best interests (and thus have no obligations of confidentiality to the child) or may serve as a traditional advocate for the preferences of the child (with confidentiality obligations to the child).

In light of this complexity and confusion about the role of a child's representative, the Model Standards do not take a position on whether the representative must be included in the mediation process. The document simply 
imposes an obligation on the mediator to inform a child's representative of the mediation: If the representative of the child chooses to participate in the mediation, the Model Standards also impose an obligation.on the mediator to discuss" the effect of the representative's participation on the confidentiality of the process with the participants. If agreements result, the mediator should provide the child's representative with them, insofar as théy rêlate to the child (Standard VIIIC; p. 539, this:volume).

\section{DOMESTIC ABUSE, CHILD ABUSE AND NEGLECT, AND FAMILY MEDIATION}

Another major innovation of the Model Standards is the concrete guidance provided for family mediators who confront domestic abuse and child abuse and neglect in their practices. Abuse of a participant and danger to children significantly challenge the mediator to shape the process in a way that promotes safety (Hart, 1990; Treuthardt, 1996).

The Model Standards do not require any victim of violence or abuse to enter into mediation. Indeed, they define "domestic abuse" more broadly than physical violence-the typical legal definition of domestic violence-to include "issues of control and intimidation" (Standard XA, p. 540 , this volume') and explicitly acknowledge that "[s]ome cases ảrế not suitable for mediation because of safety, control, or intimidation issues" (Standard XC, p. 540, this volume). The Model Standards do require the mediator to adapt a fourpart approach to the problem of family violence: training, screening, assuring safety, and reporting.

First, the Model Standards require mediators to have special training in recognizing and addressing domestic violence and child abuse and neglect before undertaking any mediation in which those elements' may be present (Standards IIA[2], IXB, and XA, pp. 535, 539, and 540, respectively, this volume). The family mediation community has thus imposed upon itself a higher obligation to understand and cope with family violence than the organized bar or the family court judiciary. Although both have recognized that training in family mediation is desirable, neither has imposed a specific obligation on its membership to receive training in that area.

Second; the Model Standards require mediators to make reasonable efforts to screen for domestic abuse. There are recognized symptoms that characterize victims of domestic abuse. This form of abuse is defined as "a pattern of assaultive and coercive behaviors; including physical, sexual, and psychological attacks, as well as economic coercion that adults ... use against their intimate partners" (Fantuzzo \& Mohr, 1999, pp. 21-22). A family and divorce mediator should be trained to recognize those symptoms and respond with appropriate safety measures. A mediator is not required, however to follow any particular method of screening, because the drafters of the Model Standards were not aware of any method that has attained universal validity and could be 
accomplished with reasonable effort by the mediator. Nor do the Model Standards impose an obligation on the mediator to screen a family for child abuse and neglect-a task that requires a professional with special expertise and which results from an in-depth evaluation of the family, particularly for sexual abuse. Children rarely participate personally in mediation sessions (per Standard VIIID, p. 539, this volume). The drafters felt it was unreasonable to impose a screening obligation for child abuse and neglect on mediators when they do not usually have the opportunity to personally observe the physical and emotional conditions of participants' children. The Model Standards do require, however, that if the mediator reasonably believes that child abuse and neglect exist, he or she must comply with applicable child protection reporting laws (per Standard IXC, p. 539, this volume).

Third, the Model Standards require mediators to take steps to shape the mediation process to assure the physical safety of mediation participants. If domestic abuse exists, the Standards give the mediator a list of possible ways to assure victim safety during the mediation process including:

1. establishing appropriate security arrangements;

2. holding separate sessions with the participants even without the agreement of all participants;

3. allowing a friend, representative, advocate, counsel or attorney to attend the mediation sessions;

4. encouraging the participants to be represented by an attorney, counsel or an advocate throughout the mediation process;

5. referring the participants to appropriate community resources;

6. suspending or terminating the mediation sessions, with appropriate steps to protect the safety of the participants. (Standard $\mathrm{XD}[1-6]$, p. 540, this volume)

The Model Standards do not require the mediator to take any of these alternative courses of action. Rather, the mediator is required to consider these alternatives, and any other that might be appropriate, to respond to domestic abuse in a manner that ensures safety. The mediator is also required to facilitate the development of parenting plans that "protect the physical safety and psychological well-being of . [participants] and their children" (Standard XE, p. 540, this volume).

The Model Standards provide fewer options for a mediator to respond to a situation where the mediator reasonably believes child abuse or neglect exists. The mediator, as mentioned above, is obligated to comply with applicable child protection laws. The mediator is also asked to encourage the participants to explore appropriate services and to consider suspending or terminating the mediation process in light of the allegations of child abuse and neglect (per Standard IXC[1-2], p. 539, this volume).

Finally, as previously discussed, the Model Standards modify the requirement of confidentiality in the mediation process in light of the vital public policy to protect against family violence. They require mediators to inform 
participants of any ethically or legally mandated reporting requirements, such as the obligation to report child abuse and neglect, before mediation begins (per Standard VIIB, p. 538, this volume). The Model Standards also require mediators" to report "a participant's threat of suicide or violence against any person to the threatened.person and the appropriate authorities if the mediator believes such threat is likely to be.acted upon" and the disclo: sure is otherwise permitted by law (perr Standard VIIC, p. 538, this volume). Finally, mediators should consider suspending or terminating the mediation process if "the safety of a participant or the well-being of a child is threatened" by its continuation (Standard.XIA[1], p. 540, this volume).

\section{CONCLUSION}

The Model Standards are a commitment by the mediation profession to excellence in professional practice to benefit families and çhildren. The court system, the bar, and the public increasingly recognize that participants in family disputes benefit from participation in these standards. The mediation profession's voluntary adherence to the Model Standards that it developed itself will accelerate and strengthen that trend.

\section{APPENDIX 22.1. MODEL STANDARDS OF PRACTICE FOR FAMILY AND DIVORCE MEDIATION}

Overview and Definitions

Family and divorce mediation ("family mediation" or "mediation") is a process in which a mediator, an impartial third party, facilitates the resolution of family disputes by promoting the participants' voluntary agreement. The family mediator assists communication, encourages understanding and focuses the participants on their individual and common interests. The family mediator works with the participants to explore options, make decisions and reach their own agreements.

Family mediation is not a substitute for the need for family members to obtain independent legal advice or counseling or therapy. Nor is it appropriate for all families. However, experience has established that family mediation is a valuable option for many families because it can:

- increase the self-determination of participants and their ability to communicate;

- promote the best interests of children; and

- reduce the economic and emotional costs associated with the resolution of family disputes. 
Effective mediation requires that the family mediator be qualified by training, experience and temperament; that the'mediator be impartial; that the participants reach their decisions voluntarily; that their decisions be based on sufficient factual data; that the mediator be aware of the impact of culture and diversity; and that the best interests of children be taken into account. Further, the mediator should also be prepared to identify families whose historý includes domestic abuse' or child abuse.

These Model'Standards of Practice for Family and Divorce Mediation ("Model Standards") $)_{x}$ aim to perform three major functions:

-to serve as a guide for the conduct of family mediators;

- to inform the mediating participants of what they can expect; and

- to promote public confidence in mediation as a process for resolving family disputes.

The Model Standards are aspirational in character. They describe good practices for family mediators. They are not intended to create legal rules or standards of liability.

The Model Standards include different levels of guidance:

- Use of the term "may" in a Stardard is the lowest strength of guidance and indicates' a practice that the family mediator should consider adopting but which can be deviated from in the exercise of good professional judgment.

- Most of the Standards employ the term "should" which indicates that the practice described in the Standard is highly desirable and should be departed from only with very'strong reasoin $n_{i *}$

- The rarer use of the term "shall" in a Standard is a higher level of guidance to the family mediator, indicating that the mediator should not have discretion to depart from the practice described.

Standard I

A family mediator shall recognize that mediation is based on the principle of self-determination by the participants.

A. Self-determination is the fundamental principle of family mediation. The mediation process relies upon the ability of participants to make their own voluntary and informed decisions.

B. The primary role of a family mediator is to assist the participants to gain a better understanding of their own needs and interests and the needs and interests of .others and to facilitate agreement among the participants.

C. A family mediator should inform the participants that they may seek information and advice from a variety of sources during the mediation process.

D. A family mediator shall inform the participants that they may withdraw from family mediation at any time and are not required to reach an agreement in mediation. 
E. The family mediator's commitment shall be to the participants and the process. Pressure from outside of the mediation process shall never influence the mediator to coerce participants to settle.

Standard II

A family mediator shall be qualified by education and training to undertake the mediqtion.

A. To perform the family mediator's role, a mediator should:

1. have knowledge of family law;

2. have knowledge of and training in the impact of family conflict on parents, children and other participants, including knowledge of child, deyelopment, domestic abuse and child abuse and neglect;

3. have education and training specific to the process of mediation;

4. be able to recognize the impact of culture and diversity.

B. Family mediators should provide information to the participants about the mediator's relevant training, education and expertise.

Stangard III

A family mediator shall facilitate the participants: understanding of what mediation is and assess their capacity to mediate before the participants reach an agreement to mediate.

A. Before family mediation begins a mediator should provide the participants with an overview of the process and its purposes, including:

1. informing the participants that reaching an agreement in family mediation is

- consensual in nature, that a mediator is an impartial facilitator, and that a mediator may not impose or force any settlement on, the parties;

2. distinguishing family mediation from other processes designed to address family issues and disputes;

3. informing the participants that any agreements reached will be reviewed by the court when court approval is ${ }_{i}$ required;

4, informing the participants that they may obtain independent advice from attorneys, counsel, advocates, accountants, therapists or other professionals during the mediation process;

5. advising the participants, in appropriate cases, that they can seek the advice of religious figures, elders or other significant persons in their community whose opinions they value;

6. discussing, if applicable, the issue of separate sessions with the participants, a description of the circumstances in which the mediator may:meet alone with any 'of the participants, or with any third party and the conditions of confidentiality concerning these separate seşsions;

7. informing the participants that the presence or absence of other persons at a mediation, including attorneys, counselors or advocates, deppends on the agreement of the participants and the mediator, unless a statute or regulation 
otherwise requires or the mediator believes that the presence of another person is required or may be beneficial because of a history or threat of violence or other serious coercive activity by a participant.

8. describing the obligations of the mediator to maintain the confidentiality of the mediation process and its results as well as any exceptions to confidentiality;

9. advising the participants of the circumstances under which the mediator may suspend or terminate the mediation process and that a participant has a right to suspend or terminate mediation at any time.

B. The participants should sign a written agreement to mediate their dispute and the terms and conditions thereof within a reasonable time after first consulting the family mediator.

C. The family mediator should be alert to the capacity and willingness of the participants to mediate before proceeding with the mediation and throughout the process. A mediator should not agree to conduct the mediation if the mediator reasonably believes one or more of the participants is unable or unwilling to participate.

D. Family mediators should not accept a dispute for mediation if they cannot satisfy the expectations of the participants concerning the timing of the process.

Standard IV

A family mediator shall conduct the mediation process in an impartial manner. A family medi. ator shall disclose all actual and potential grounds of bias and conflicts of interest reasonably known to the mediator. The participants shall be free to retain the mediator by an informed, written waiver of the conflict of interest. However, if a bias or conflict of interest clearly im. pairs a mediator's impartiality, the mediator shall withdraw regardless 'of the express agreement of the participants.

A. Impartiality means freedom from favoritism or bias in word, action or appearance, and includes a commitment to assist all participants as opposed to any one individual.

B. Conflict of interest means any relationship between the mediator, any participant or the subject matter of the dispute, that compromises or appears to compromise the mediator's impartiality.

C. A family mediator should not accept a dispute for mediation if the family mediator cannot be impartial.

D. A family mediator should identify and disclose potential grounds of bias or conflict of interest upon which a mediator's impartiality might reasonably be questioned. Such disclosure should be made prior to the start of a mediation and in time to allow the participants to select an alternate mediator.

E. A family mediator should resolve all doubts in favor of disclosure. All disclosures should be made as soon as practical after the mediator becomes aware of the bias or potential conflict of interest. The duty to disclose is a continuing duty. 
F. A family mediator should guard against bias or partiality based on the participants' personal characteristics, background or performance at the mediation.

G. A family mediator should avoid conflicts of interest in recommending the services of other professionals.

$\mathrm{H}$. A family mediator shall not use information about participants obtained in a mediation for personal gain or advantage

I. A family mediator should withdraw pursuant to Standard IX if the mediator believes the mediator's impartiality has been compromised or a conflict'of interest has been identified and has not been waived by the participants.

Standard V

A family mediator shall fully disclose and explain the basis of any compensation, fees and charges to the participants.

A. The participants should be provided with sufficient information about fees at the outset of mediation to determine if they wish to retain the services' of the mediator.

B. The participants' written agreement to mediate their dispute should include a description of their fee arrangement with the mediator.

C. A mediator should not enter into a fee agreement which is contingent upon the results of the mediation or the amount of the settlement.

D. A mediator should not accept a fee for referral of a matter to another mediator or to any other person.

E. Upon termination of mediation a mediator should return any unearned fee to the participants.

Standard VI

A family mediator shall structure the mediation process so that the participants make decisions based on sufficient information and knowledge.

A. The mediator should facilitate full and accurate, disclosure and the acquisition and development of information during mediation so that the participants can make informed decisions. This may be accomplished by encouraging participants to consult appropriate experts.

B. Consistent with standards of impartiality and preserving participant self-determination, a mediator may provide the participants with information that the mediator is qualified by training or experience to provide. The mediator shall not provide therapy or legal advice.

C. The mediator should recommend that the participants obtain independent legal representation before concluding an agreement.

D. If the participants so desire, the mediator should allow attorneys, counsel or advocates for the participants to be present at the mediation sessions.

E. With the agreement of the participants, the mediator may document the participants' resolution of their dispute. The mediator should inform the participants that any agreement should be reviewed by an independent attorney before it is signed. 
Standard VII

A family mediator shall maintain the confidentiality of all information acquired in the mediation process, unless the mediator is permitted or required to reveal the information by law or agreement of the participants.

A: The mediator should discuss the participants' expectations of confidentiality with them prior to undertaking the mediation: The written agreement to mediate should include provisions concerning confidentiality.

B. Prior to undertaking the mediation the mediator should inform the participants of the limitations of confidentiality such as statutory, judicially or ethically mandated reporting.

C. The mediator shall disclose a participant's threat of suicide or violence against any person to the threatened person and the appropriate authorities if the mediator believes such threat is likely to be acted upon as permitted by law.

D. If the mediator holds private sessions with a participant, the obligations of confidentiality concerning those sessions should be discussed and agreed upon prior to the sessions.

E. If subpoenaed or otherwise noticed to testify or to produce documents the mediator should inform the participants immediately: The mediator'should not testify or provide documents in response to a subpoena without an order of the court if the mediator reasonably believes doing so would violate an obligation of confidentiality to the participants.

Standard VIII

A family mediator shall assist participants in determining how to promote the best interests of children.

A. The mediator should encourage the participants to explore the range of options available for separation or post divorce párenting arrangements and their respective costs and benefits. Referral to a specialist in child development may be appropriate for these purposes. The topics for discussion may include, among others:

1. information about community resources and programs that can help the participants and their children cope with the consequences of family reorganization and family' violence;

2. problems that continuing conflict creates for children's development and what steps might be taken to ameliorate the effects of conflict on the children;

3. development of a parenting plan that covers the children's physical residence and decision-making responsibilities for the children, with appropriate levels of detail as agreed to by the participants;

4. the possible need to revise parehting plans as the developmental needs of the children evolve over time; and 
5. encouragement to the participants to develop appropriate dispute resolution mechanisms to facilitate future revisions of the parenting plan.

B. The mediator should be sensitive to the impact of culture and religion on parenting philosophy and other decisions.

C. The mediator shall inform any court-appointed representative for the children of the mediation. If a representative for the children participates, the mediator should, at the outset, discuss the effect of that participation on the mediation process and the confidentiality of the mediation with the participants. Whether the representative of the children participates or not, the mediator shall provide the representative with the resulting agreements insofar as they relate to the children.

D. Except in extraordinary circumstances, the children should not participate in the mediation process without the consent of both parents and the children's courtappointed representative.

E. Prior to including the children in the mediation process, the mediator should consult with the parents and the children's court-appointed representative about whether the children should participate in the mediation process and the,form of that participation.

F. The mediator should inform all concerned about the available options for the children's participation (which may include personal participation, an interview with a mental health professional, or the mediator reporting to the parents, or a videotape statement) and discuss the costs and benefits of each with the participants.

\section{Standard IX}

A family mediator shall recognize a family situation involving child abuse or neglect and take appropriate steps to shape the mediation process accordingly.

A. As used in these Standards, child abuse or neglect is defined by applicable state law.

B. A mediator shall not undertake a mediation in which the family situation has been assessed to involve child abuse or neglect without appropriate and adequate training.

C. If the mediator has reasonable grounds to believe that a child of the participants is abused or neglected within the meaning of the jurisdiction's child abuse and neglect laws, the mediator shall comply.with applicable child protection laws.

1. The mediator should encourage the participants to explore appropriate services for the family.

2. The mediator should consider the appropriateness of suspending or terminating the mediation process in light of the allegations.

Standard X

A family mediator shall recognize a family situation involving domestic abuse and take appropriate steps to shape the mediation process accordingly. 
A. As used in these Standards, domestic abuse includes domestic violence as defined by applicable state law and issues of control and intimidation.

B. A mediator.shall not undertake a mediation in which the family situation has been assessed to involve domestic abuse without appropriate and adequate training.

C. Some cases are not suitable for mediation because of safety, control or intimidation issues. A mediator should make a reasonable effort to screen for the existence of domestic abuse prior to entering into an agreement to mediate. The mediator should continue to assess for domestic abuse throughout the mediation process.

D. If domestic abuse appears to be present the mediator shall consider taking measures to insure the safety of participants. and the mediator including, among others:

1. establishing appropriate security arrangements;

2. holding separate sessions with the participants even without the agreement of all participants;

3. allowing a friend, representative, advocate, counsel or attorney to attend the mediation sessions;

4. encouraging the participants to be represented by an attorney, counsel or an advocate throughout the mediation process;

5. referring the participants to appropriate community resources;

6. suspending or terminating the mediation sessions, with appropriate steps to protect the safety of the participants.

E. The mediator should facilitate the participants' formulation of parenting plans that protect the physical safety and psychological well-being of themselves and their children.

Standard XI

A family:mediator shall suspend or terminate the mediation process when the mediator reasonably believes that a participant is unable to effectively participate or for other compelling reasons.

A. Circumstances under which a mediator should consider suspending or terminating the mediation, may include, among others:

1. the safety of a participant or well-being of a child is threatened;

2. a participant has or is threatening to abduct a child;

3. a participant is unable to participate due to the influence of drugs, alcohol, or physical or mental condition;

4. the participants are about to enter into an agreement that the mediator reasonably believes to be unconscionable;

5. a participant is using the mediation to further illegal conduct;

6. a participant is using the mediation process to gain an unfair advantage;

7. if the mediator believes the mediaton's impartiality has been compromised in accordance with Standard IV. 
B. If the mediator, does suspend or terminate the mediation, the mediator should " take all reasonable șteps to minimize prejudice or inconvenience to the participants which may ${ }_{\text {result. }}$

Standard XII

)

A family mediator shall be truthful in the advertisement and solicitation for mediation.

A. Mediators should refrain from promises and guarantees of results. A mediator should not advertise statistical settlement data or settlement rates.

B. Mediators should accurately represent their qualifications. In an advertisement or other communication, a mediátor may make reference to meeting state, national, or private organizational qualifications only if the entity referred to has a procedure for qualifying mediators and the mediator has been duly granted the requisite status.

Standard XIII

A family mediator shall acquire and maintain professional competence in mediation.

A. Mediators should continuously improve their professional skills and abilities by, among other activities, participating in relevant continuing education programs ánd should regularly engage in self-assessment.

B. Mediators should participate in programs of peer consultation and should help train and mentor the work of less experienced mediators.

C. Mediators should continuously strive to understand the impact of culture and, di; versity on the mediator's practice.

Appendix: Special Policy Considerations for State Regulation of Family Mediators and Court Affiliated Programs

The Model Standards recognize the National Standards for Court Conniected Dispute Resolution Programs (1992). There are also state and local regulations governing such programs and family mediators. The following principles of organization and practice, however, are especially important for regulation of mediators and court-connected family mediation programs. They are worthy of separate mention.

A. Individual states or local courts should set standards and qualifications for family mediators including procedures for evaluations and handling grievances ągainst mediators. In developing these standards $s_{i}$ and qualifications, regulators should consult with appropriate professional groúps, including professional associations of family mediators.

B. When family mediators are appointed by a court or other institution, the appointing agency'should make reásonable éfforts tó insure that each mediator is qualified for the appointment. If a list of family mediators qualified for court appointr. ment exists, the requirements for being included on the list should be made public and available to all interested persons. 
C. Confidentiality should not be construed to limit or prohibit the effective monitoring, research, evaluation or monitoring of mediation programs by responsible individuals or academic institutions provided that no identifying information about any person involved in the mediation is disclosed without their prior written consent. Under appropriate circumstances, researchers may be permitted to obtain access to statistical data and, with the permission of the participants, to individual case files, observations of live mediations, and interviews with participants.

\section{ACKNOWLEDGMENTS}

The views expressed in this chapter are my own; they have not been approved by the American Bar Association, AFCC, or any of the other groups or individuals who participated in the symposium or any group that has adopted the Model Standards. This chapter is adapted from Schepard (2001). Adapted by permission of the American Bar Association Section of Family Law.

\section{NOTES}

1. The National Council of Dispute Resolution Organization is an umbrella organization that includes the Academy of Family Mediators, the American Bar Association Section of Dispute Resolution, AFCC, Conflict Resolution Education Network, the National Association for Community Mediation, the National Conference, on Peacemaking and Conflict Resolution, and the Society of Professionals in Dispute Resolution.

2. Uniform Mediation Act (May 4, 2001 Draft). More information about the Uniform Mediation Act can be obtained at www.pon.harvard.edu/guests/uma. 2001 draft).

3. Uniform Mediation Act, section 2(1), working note on importance of candor (May 4,

4. Uniform Mediation Act, working note on subsections 7(a)(3) and 7(a)(5) (May 4, 2001 draft).

\section{REFERENCES}

American Bar Association. (1984). Standards of Practice for Lawyer Mediators in Family Disputes. In Dispute resolution: Negotiation, mediation, and other processes (pp. 469-474). Boston, MA: Little, Brown.

Beyer, J. (1998). Practicing law at the margins: Surveying ethics rules for legal assistants and lawyers who mediate. Georgia Journal of Legal Ethics, 11, 411-420.

Fantuzzo, J. W., \& Mohr, W. K. (1999). Prevalence and effects of child exposure to domestic violence. The Future of Children: Domestic Violence and Children, 9, 21-32.

Hart, B. (1990). Gentle jeopardy: The further endangerment of battered women in custody mediation. Mediation Quarterly, 7, 317-330.

Mcewen, C. A., Rogers, N. H., \& Maiman, R. J. (1995). Bring in the lawyers: Challenging the dominant approaches to insuring fairness in divorce mediation. Minnesota Law Review, 79, 1317-1411. 
Schepard, A. (1985). Taking children seriously: Promoting cooperative custody after divorce. Texas Law Review, 64, 687-788.

Schepard, A. (1998). Parental conflict prevention programs and the unified family court: A public health perspective. Family Law Quarterly, 32(95), 103-105.

Schepard, A. (2000). The evolving judicial role in child custody disputes: From fault finder to conflict manager to differential case management. University of Arkansas at Little Rock Law Review, 22, 395-428.

Schepard, A. (2001). Mqdel standards of practice for family and divorce mediation: The

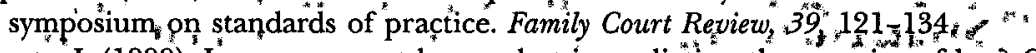

Schwartz, J. (1999). Laymen cannot lawyer, but is mediation the practice of law? Cardozo Law Review, 20, 1715-1745.

Silberman, L. (1982). Professional responsibility problems of divorce mediation. Family Law Quarterly, 16, 107-145.

Stern, H., P., Mellon, M. W., Butler, B. O., Stroh, S. E., Long, N., \& Jones, J. G. (2000). Battered child syndrome: Is it a paradigm for a child of embattled divorce? University of Arkansas at Little Rock Law Review, 22, 335-355.

Symposium on Standards of Practice for Family and Divorce Mediation convened by the Association of Family and Conciliation Courts. (1984). Model standards of practice for family and divorce mediation.

Symposium on Standards of Practice for Family"and Divórce Mediation convened by the Association of Family and Conciliation Courts. (2000). Modèl stảndards of practice for divorce and family mediators. Family and Conciliation Courts Review, 38, 106-122.

Treuthart, M. (1996). All that glitters is not gold: Mediation in domestioabuse cases. Clearinghouse Review, 30, 243-260.

Weller, S., Martin, J. A., \& Lederach, J. P. (2001), Fostering culturally responsive courts: The case of family dispute resolution for Latinos. Family Court Review, 39, 185-202. 